\title{
IDPoor: a poverty identification programme that enables collaboration across sectors for maternal and child health in Cambodia
}

\author{
Mary White Kaba and colleagues describe how Cambodia's national poverty identification \\ system, IDPoor, has provided a nexus for different sectors' contributions to maternal and child \\ health among the poor
}

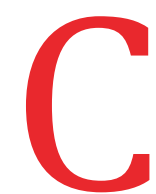

ambodia has made impressive progress in reducing poverty and improving maternal and child health $(\mathrm{MCH})$, being one of the few countries to have achieved its Millennium Development Goal 4 and 5 targets. ${ }^{1}$ National health indicators show improvements in access to reproductive, maternal, and child health services, but also decreasing equity gaps between different wealth quintiles, as demonstrated by national demographic and health surveys between 2000 and $2014 .^{2}$ Underlying this progress has been the commitment by both the Royal Government of Cambodia (RGC) and development partners to focus

\section{KEY MESSAGES}

- IDPoor, Cambodia's nationwide, community based poverty identification system, is a social registry that is evolving to become an important building block in Cambodia's comprehensive National Social Protection Policy Framework and efforts towards universal health coverage

- IDPoor reduces fragmentation of development efforts through shared data that enable different sectors to channel complementary support to the same poor households, which are given equity cards

- All development programmes are obliged by law to identify their target group using IDPoor data, many of them directly or indirectly supporting improved $\mathrm{MCH}$, while partners can input to the IDPoor mechanism, which is adaptive to sectors' needs and demands

- IDPoor's contribution to improving equity in $\mathrm{MCH}$ is mediated through social assistance programmes, including the nationwide Health Equity Fund. attention on the poorest to improve equity (supplement 1).

A variety of governmental and nongovernmental programmes aim to support the poorest to access social assistance interventions in health and other sectorswith a frequent focus on women and children. Such beneficiaries are identified by a nationwide programme, implemented by the Ministry of Planning (MoP): the Identification of Poor Households Programme (IDPoor). IDPoor serves as a social registry of poor and vulnerable households, a component towards a comprehensive social protection system.

As an increasing number of low and middle income countries (LMICs) institute information systems for social protection, we analyse Cambodia's IDPoor system as a case study to identify the opportunities and challenges it presents for cross sectoral action in support of MCH. We examine how IDPoor has contributed to collaboration across sectors benefiting women and children, before assessing how the use of IDPoor data may have supported improved equity in MCH in Cambodia.

This case study was developed in response to a global call for proposals by the Partnership for Maternal, Newborn, and Child Health, with the objective of identifying success factors of multisectoral collaboration for women's, children's, and adolescent health. Methods used in this case study included a review of literature and of available data, interviews with key informants to inform a working report, and a multi-stakeholder workshop to review the findings of the working report (supplement 2).

\section{Poverty identification in IDPoor}

Poverty levels in Cambodia have decreased substantially-from $47.8 \%$ of the population in 2007 to $13.5 \%$ in $2015 .^{3}$ Nevertheless, a large proportion of non-poor households sit just above the national pov- erty threshold and are vulnerable to falling back into poverty. ${ }^{4}$

The relation between poverty and poor health is well established. In poverty reduction, the targeting of services to those most in need is a common approach, including as a strategy within universal policies. ${ }^{5}$ Even though targeting is generally exposed to trade-off compromises between accuracy and workability, many countries have opted to prioritise access to health and social services for the poorest on the grounds of both efficiency and equity. To guide targeted delivery of services, at least 30 LMICs have developed some type of social protection information system, mostly social registries. In principle these also create the potential to align different social assistance programmes. ${ }^{6}$ Given the proliferation of such schemes and the importance of promoting $\mathrm{MCH}$ through sectors such as health and education, ${ }^{7}$ we seek to document what integration across sectors can be achieved through an example of a social registry in a LMIC.

IDPoor is central to the RGC's efforts to promote equity, with a mandate to identify the poor for targeting by health and social programmes across multiple sectors. ${ }^{8}$ Since 2011, Cambodia's Sub-Decree 291 has made it mandatory for all programmes targeting the poor to use IDPoor data for analysis, planning, and implementation.

IDPoor's origin is linked to the introduction of the national Health Equity Fund (HEF). After government health facilities introduced user fees in 1996, HEF grew out of the need to reduce financial access barriers for poor people in a standardised way. Health facilities faced the challenge of assessing poor patients' claims for fee exemptions without a systematic process, making it vulnerable to inconsistencies and with limited effectiveness in protecting poor Cambodians. ${ }^{9}$ At the same time, the social assistance landscape in 
Cambodia was fragmented, with different programmes operating across sectors, each implementing its own poverty targeting mechanism. ${ }^{10}$ In response, in 2005 the MoP, together with development partners, began formulating a national, cross sectoral poverty identification mechanism, which could serve multiple social assistance programmes. Active involvement of relevant ministries at national and sub-national level, communal structures, non-governmental organisations, and development partners helped to build a consensus on the national guidelines and contributed to wide acceptance of IDPoor.

To identify households affected by multidimensional poverty, IDPoor combines proxy means testing, whereby poverty identification is done on the basis of observable household characteristics and assets (supplement 3), and community based targeting, applying an iterative, participatory consultation process to ensure community consensus on who is poor (fig 1). Safeguards are in place to ensure an open process acceptable to both communities and development programmes (box 1). Households confirmed as poor are given an equity card, which gives access to support from a variety of sectors, including healthcare in public facilities, covered by HEF.
Launched in 2007, poverty identification is carried out in a third of Cambodia's provinces each year, thereby covering each village once every three years. IDPoor initially focused on rural areas, where $80 \%$ of Cambodia's population-and $90 \%$ of those below the poverty line -live, but since 2016 the programme has broadened to include urban areas. The community based process makes systematic, nationwide poverty identification affordable and sustainable for the RGC. Though initially funded by donors, the IDPoor programme in rural areas has transitioned to entirely domestic funding and management by the RGC.

The IDPoor database provides poverty data for the entire country through the IDPoor Information System, allowing registered users-governmental and non-governmental organisations and programmes providing social services for the poor-to access a set of standard reports online or, upon request, in the form of books or DVDs. Different levels of data access exist, and sensitive data are only available to those programmes that have undergone a special registration process.

\section{IDPoor's contribution to collaboration between sectors}

The number of organisations using IDPoor data to channel their support to poor families tripled between 2012 and 2015, from 42 to 136 . This represents $62 \%$ of all development programmes assessed in a 2015 study. ${ }^{13}$ These programmes had on average 800000 beneficiaries, although the degree of geographical and beneficiary coverage varied substantially. Among those using IDPoor data, 94\% considered it an important tool. Most used these data for targeting individual households (84\%) or for geographical targeting based on poverty levels (64\%). Some 37 programmes explicitly sought to reach women and children. These came from a range of sectors-including education (35\%), agriculture and rural development (24\%), human rights (19\%), and health (14\%)-and provided different services to beneficiaries such as training (78\%), livelihood development (30\%), and food assistance $(19 \%)$. $^{13}$

Programmes that use IDPoor data and specifically tackle the health and wellbeing of women and children include both those that implement sector specific interventions and others that apply a multi-sectoral approach, bringing together interventions from different sectors. These programmes encompass a range of activities, including cash transfers, scholarships, food, or capacity building (table 1 and supplement 4).

By using IDPoor data, programmes from different sectors reach the same

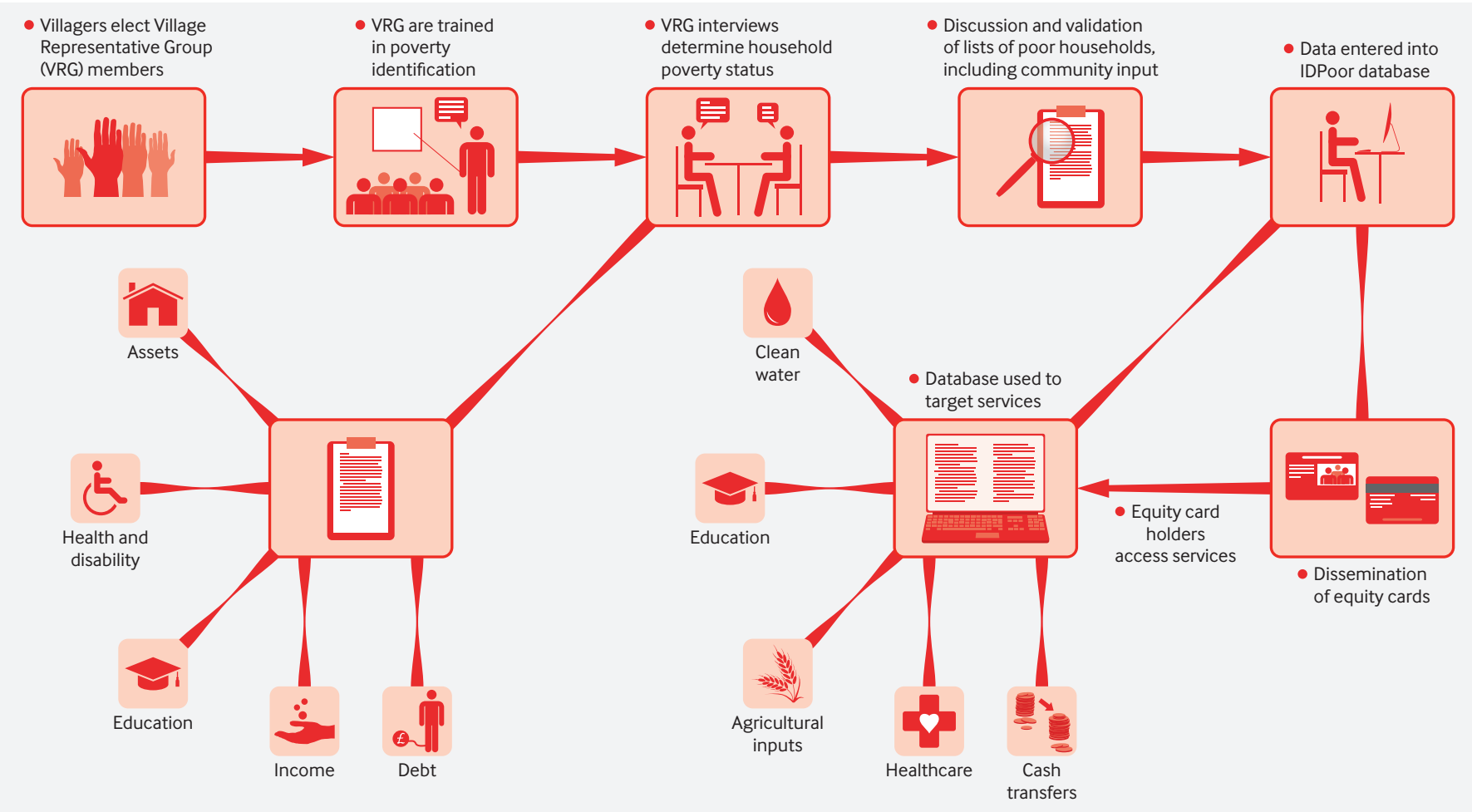

Fig 1 | The IDPoor process ${ }^{10}$ 
Box 1: Functioning and safeguards of the IDPoor process

In each round of IDPoor, an estimated 35000 people are actively involved.

Villagers select representative groups who conduct household interviews using a standardised questionnaire, and present draft lists of poor households to the community for feedback and validation. To ensure an open process, the draft and final lists of poor households must be publicly displayed, allowing for community validation of identified beneficiaries.

Local non-governmental organisations are invited to participate in the process to ensure inclusion of specific vulnerable groups. Throughout the process, the MoP provides training, monitors implementation, and gives ongoing technical support. Once a community has ratified a household's poverty status, IDPoor gives an equity card to the household indicating its status ("1" for extremely poor and " 2 " for moderately poor).

Any poverty targeting methodology is a compromise, weighing level of accuracy against available resources and other considerations. ${ }^{11}$ IDPoor's hybrid poverty identification methodology aims to combine the advantages of both proxy means testing and community based targeting, helping to ensure acceptance through the involvement of the community, together with use of consistent criteria in order to reduce the risk of bias. ${ }^{10}$

Poverty identification is commonly affected, to a certain degree, by exclusion (non-included poor households) or inclusion errors (included non-poor households). Although it is difficult to quantify such errors, a World Bank assessment determined that, on average, surveyed households rated the accuracy and implementation of the IDPoor process as high. ${ }^{12} \mathrm{~A}$ systematic assessment by IDPoor of its own procedures and whether their implementation may introduce errors is under way from September 2018.

Although it cannot be ruled out that the possession of an equity card can lead to stigmatisation of poor households, no evidence could be found to support this assumption in Cambodia. Rather, it appears that villagers are usually aware of the socioeconomic situation of their community, which is a central premise of the IDPoor process and its reliance on villagers to identify those who are living in poverty.

identified set of beneficiaries. This allows for complementarity and greater alignment of efforts, even without active coordination among actors. Most programmes use IDPoor data because they fit their needs (69\%), are legally required (21\%), or are free $(16 \%){ }^{13}$

These points were corroborated at a multi-stakeholder review meeting (supplement 2), where participants described IDPoor as an important basis for the interventions of both governmental and non-governmental organisations. There was particular appreciation that IDPoor removes the burden on programmes to set up their own targeting systems. A problem raised was the limited feedback from programmes to IDPoor on how they use the data, as well as limited exchange between data user programmes targeting the poor. This presents a challenge for more effective collaboration as well as for monitoring the use of IDPoor data, and raised the question of the extent to which IDPoor should assume a stronger coordination function to guide productive synergies between programmes across sectors.

Additional multisectoral interaction relates to the development and refinement of the IDPoor tools and methodologies. A mechanism of regular consultation between MoP and the Ministries of Health, Education, Interior, and Social Affairs as well as development partners has been integral to IDPoor processes since the start. ${ }^{10}$ Urban IDPoor, for instance, originated from the desire of development programmes to expand IDPoor to urban areas, and also to include further indicators tackling vulnerabilities such as disability, chronic illness, debt, and low levels of education. In 2018, responding to partners' concerns that IDPoor's three year poverty identification cycle missed important demographic or socioeconomic changes occurring in the interval, the MoP started a new community based pilot, “On-Demand IDPoor," as a standardised option to register new households and household members in between the regular three year poverty identification rounds. This demand for more up-to-date poverty and demographic data-such as new household members, households that slip below the poverty line, or work related migration-was particularly strong on the part of $\mathrm{MCH}$ programmes, whose priority groups of pregnant women and children under 2 years old change from month to month. Both the Urban and the On-Demand IDPoor processes are examples of how IDPoor has adjusted its mechanisms over the past few years to make poverty data more responsive to the needs of different sectoral programmes. A permanent IDPoor Improvement Working Group was instituted in 2018 to advise IDPoor on enhancing its processes and contributing to the implementation of the national social protection framework, and is expected to intensify cooperation among social assistance programmes.

\section{IDPoor's contribution to equity in MCH}

IDPoor data from the 2015-17 cycle show that more than one quarter of the 2.2 million people in its database are women of reproductive age (15 to 49 years) and another 30\% are children under 15 . Thus, over $50 \%$ of IDPoor household members are potential users of MCH programmes. ${ }^{18}$ IDPoor itself creates opportunities for access, mostly through distributing equity cards, but also by partners' use of IDPoor data for planning service delivery. The actual contribution of IDPoor to equity in $\mathrm{MCH}$ will depend on the effectiveness of the programmes that are implemented by organisations using its data.

While we have documented the utilisation of IDPoor data for the targeting and implementation of programmes across multiple sectors, the programme has not yet advanced to a stage where it systematically captures data on the supply and uptake of such services. For this reason, it is not possible to analyse data on actual, concurrent, or subsequent uptake of such services by equity card holders. We can, however, examine the success of single programmes backed by IDPoor data in achieving greater use of services supporting MCH. For example, access to antenatal care, delivery, and family planning services is provided without charge at point of delivery to equity card holders through HEF, the single largest programme backed by IDPoor data (box 2). The contribution of HEF to reducing out-ofpocket expenditures for health services has also been documented. ${ }^{19} 20$

HEF (and indirectly IDPoor) may enable access to MCH services for poor women and children that they would otherwise be unable to afford. Overall, existing published evidence on whether HEF increases general uptake of public health services among entitled poor people remains mixed. ${ }^{192425}$ 


\begin{tabular}{|c|c|c|c|c|c|}
\hline Programme & Sector & Type of intervention & Eligibility & Coverage & Agency \\
\hline $\begin{array}{l}\text { Health Equity Fund } \\
\text { (ongoing) }\end{array}$ & Health & $\begin{array}{l}\text { Provides health services free at } \\
\text { point of delivery, transportation } \\
\text { to health facilities, food during } \\
\text { treatment at hospital }\end{array}$ & IDPoor 1 and 2 households & Nationwide (all provinces) & $\begin{array}{l}\text { Ministry of Health, multiple } \\
\text { international donors }\end{array}$ \\
\hline $\begin{array}{l}\text { Vouchers for reproductive } \\
\text { healthcare services } \\
(2011-17)\end{array}$ & Health & $\begin{array}{l}\text { Provided vouchers for essential } \\
\text { healthcare related to pregnancy, } \\
\text { birth, and family planning }\end{array}$ & $\begin{array}{l}\text { Vouchers were distributed to } \\
\text { IDPoor cardholders (IDPoor } 1 \text { and } \\
2 \text { households) }\end{array}$ & Three provinces & $\begin{array}{l}\text { Ministry of Health, KfW } \\
\text { Development Bank }\end{array}$ \\
\hline $\begin{array}{l}\text { Cash transfer for poor } \\
\text { families with pregnant } \\
\text { mothers or children under } \\
\text { five years }(2015-16)\end{array}$ & Health, nutrition & $\begin{array}{l}\text { Unconditional and conditional } \\
\text { cash transfers to increase the use } \\
\text { of essential health and ANC or } \\
\text { PNC services }\end{array}$ & $\begin{array}{l}\text { Pregnant women and children } \\
\text { under } 5 \text { (IDPoor } 1 \text { and } 2 \\
\text { households) }\end{array}$ & $\begin{array}{l}1500 \text { households in two } \\
\text { provinces }\end{array}$ & $\begin{array}{l}\text { World Bank, National Committee } \\
\text { for Sub National Democratic } \\
\text { Development Secretariat }\end{array}$ \\
\hline $\begin{array}{l}\text { NOURISH mother and } \\
\text { child nutrition cash } \\
\text { transfer incentive for } \\
\text { health service utilisation } \\
(2014-19)\end{array}$ & $\begin{array}{l}\text { Health, nutrition, } \\
\text { water and } \\
\text { sanitation, } \\
\text { agriculture }\end{array}$ & $\begin{array}{l}\text { Provides conditional cash } \\
\text { transfers to stimulate use } \\
\text { of specific nutrition and } \\
\text { reproductive health services; and } \\
\text { vouchers for WASH and nutrition } \\
\text { products }\end{array}$ & $\begin{array}{l}\text { Pregnant women and children } \\
\text { under } 2 \text { (IDPoor } 1 \text { and } 2 \\
\text { households and an additional } \\
\text { process to consider further poor } \\
\text { households not included in } \\
\text { IDPoor) }\end{array}$ & $\begin{array}{l}565 \text { villages of the } 20 \text { poorest } \\
\text { districts in three provinces } \\
\text { (selection based on a poverty rate } \\
\text { of } 30 \% \text { or higher using IDPoor } \\
\text { data) }\end{array}$ & $\begin{array}{l}\text { Save the Children; district, } \\
\text { municipality, and commune } \\
\text { authorities }\end{array}$ \\
\hline $\begin{array}{l}\text { Cash transfer pilot project } \\
\text { for pregnant women and } \\
\text { children in Cambodia } \\
(2015-17)\end{array}$ & Health, nutrition & $\begin{array}{l}\text { Unconditional and conditional } \\
\text { cash transfers to increase the use } \\
\text { of essential health and ANC/PNC } \\
\text { services }\end{array}$ & $\begin{array}{l}\text { Pregnant women and children } \\
\text { under } 5 \text { (IDPoor } 1 \text { and } 2 \\
\text { households) }\end{array}$ & $\begin{array}{l}57 \text { villages in eight communes in } \\
\text { one province }\end{array}$ & $\begin{array}{l}\text { UNICEF; Council for Agricultural } \\
\text { and Rural Development }\end{array}$ \\
\hline $\begin{array}{l}\text { Multi-sectoral Food } \\
\text { Security and Nutrition } \\
\text { (MUSEFO) (2015-20) }\end{array}$ & $\begin{array}{l}\text { Health, nutrition, } \\
\text { agriculture }\end{array}$ & $\begin{array}{l}\text { Provides training sessions to } \\
\text { farmers and families to grow a } \\
\text { more diverse range of crops and } \\
\text { improve their access to healthy } \\
\text { foods }\end{array}$ & $\begin{array}{l}\text { People vulnerable to food } \\
\text { insecurity (including IDPoor } 2 \\
\text { cardholders) }\end{array}$ & $\begin{array}{l}180 \text { villages in two provinces } \\
\text { (with families engaged in } \\
\text { agricultural activities with more } \\
\text { than } 10 \% \text { IDPoor } 2 \text { households) }\end{array}$ & $\begin{array}{l}\text { GIZ; Council for Agricultural and } \\
\text { Rural Development; provincial } \\
\text { authorities }\end{array}$ \\
\hline $\begin{array}{l}\text { Primary school } \\
\text { scholarships (2011-18) }\end{array}$ & $\begin{array}{l}\text { Nutrition, } \\
\text { education }\end{array}$ & $\begin{array}{l}\text { Provides take home rations } \\
\text { and cash transfer scholarships } \\
\text { ( } \$ 60 \text { per year) to primary school } \\
\text { children and their families }\end{array}$ & $\begin{array}{l}\text { IDPoor } 1 \text { and } 2 \text { (students in } \\
\text { grades } 4-6 \text { in schools in rural or } \\
\text { remote areas) }\end{array}$ & Sixprovinces & $\begin{array}{l}\text { Ministry of Education, Youth, and } \\
\text { Sport; World Food Programme }\end{array}$ \\
\hline $\begin{array}{l}\text { Nutrition for Under-2s } \\
\text { and Mothers Project } \\
(2015-19)\end{array}$ & Health, nutrition & $\begin{array}{l}\text { Awareness and nutrition } \\
\text { rehabilitation sessions }\end{array}$ & $\begin{array}{l}\text { Families with children under } 2 \\
\text { (IDPoor } 1 \text { and } 2 \text { households and } \\
\text { an additional process to consider } \\
\text { further poor households not } \\
\text { included in IDPoor) }\end{array}$ & 3800 households in one province & $\begin{array}{l}\text { Adventist Development and Relief } \\
\text { Agency Cambodia }\end{array}$ \\
\hline
\end{tabular}

ANC/PNC: antenatal care, postnatal care.

WASH: water, sanitation, and hygiene.

We analysed data from Cambodia's Health Management Information System between 2014 and 2017 to assess how well potential access to $\mathrm{MCH}$ services has translated into actual use by equity card holders.

A simple analysis revealed that use of MCH services among HEF supported patients has steadily risen between 2014 and 2017, at both health centre and referral hospital level (figs 2 and 3). The number of HEF covered deliveries, for example, doubled in this period, from 4013 to 7401 at referral hospital level, and from 7893 to 16237 in health centres. Uptake of antenatal services among HEF supported patients in health centres has also grown substantially during this period, from 22699 to 94653 consultations. Similarly, HEF patients' use of birth spacing services in health centres almost quadrupled to over 80000 consultations. At referral hospital level in 2017, 34\% of all paediatric consultations were covered by HEF. These increases in $\mathrm{MCH}$ service utilisation among equity card holders occurred in a context of decreasing poverty (supplement 1) and increasing healthcare use in the general population, which is reflected in a sharp increase in self paying clients and a relatively smaller share of HEF users among all patients.

Overall, these trends suggest that decreased out-of-pocket expenditures for equity card holders may have contributed to improved socioeconomic equity for these poor mothers and children. This is likely related to the combined effects of policies, programmes, and interventions that have made possible Cambodia's progress towards equitable access for poor women and children to MCH services (supplement 1). The effects of HEF as enabled by IDPoor may have worked in concert with factors such as the extension of HEF to health centres, quality improvement measures, and growing awareness of equity card entitlements.

HEF provides an example of how the link between IDPoor and a specific development programme may contribute to actual uptake beyond the theoretical access created through equity cards. However, the alleviation of financial barriers alone does not translate into uptake. While the public sector provides the vast majority of $\mathrm{MCH}$ services, there is evidence that the private sector is often consulted for primary care, including by equity card holders. ${ }^{26}$ Nonfinancial factors affecting uptake include distance to a public facility, perceived problems with quality of government health services, socio-cultural preferences such as first recourse to self medication, private or traditional providers, and limited awareness of HEF entitlements and benefits. ${ }^{27}$ These factors have implications for what poverty identification can deliver, alongside service expansion, raising awareness about entitlements, or other measures to improve acceptance, such as the improvement of service quality.

Other IDPoor data users can build on these findings. In some instances, IDPoor data may provide further opportunities to tackle these problems, such as by informing geographical targeting. With regard to other programmes, IDPoor could provide a nexus for intensified collaboration among programmes targeting the poor (to further improve cross-referrals of identified poor 


\section{Box 2: Health Equity Fund}

Cambodia's national health and social protection strategies explicitly aim for universal health coverage, and the consolidation of the Health Equity Fund (HEF) is a key element of improving financial access to healthcare for the poorest part of the population. ${ }^{21}$

HEF depends directly on IDPoor to identify its beneficiaries: all equity card holders are entitled to healthcare services without charge at point of delivery in public facilities. The Ministry of Health $(\mathrm{MoH})$ regularly obtains IDPoor data and updates its HEF patient registry, which allows health facilities to verify eligible patients. To handle non-cardholding patients claiming poverty, a "post-identification" process can be carried out at health facilities, resulting in a temporary healthcare access card valid for one year. This temporary card accounts for about $5 \%$ of all $\mathrm{HEF}$ beneficiaries. $\mathrm{MoH}$ can recommend such families to MoP for inclusion in the IDPoor identification process. Initially limited to referral hospitals, HEF coverage has been extended to health centres and, since 2015, includes all government health facilities in Cambodia.

$\mathrm{HEF}$ is a demand side financing mechanism to cover user fee exemptions for the identified poor at government health facilities, and directly reimburses these facilities for the services provided. HEF covers user fees of poor patients for all services at all levels of health facilities, including a minimum service package at health centre level, comprising basic treatment and preventive care, maternal healthcare, and newborn delivery; and a complementary package at referral hospital level to tackle more complex health problems, including surgical care. Poor patients are also entitled to non-medical benefits such as reimbursement of transportation costs to and from the referral hospital, food allowances for caretakers of patients, and funeral support. ${ }^{22}$

Based on a patient's equity card number, in 2011 HEF introduced a Patient Management and Registration System in referral hospitals, which enables patient data management and reimbursements to cardholders for costs related to transport and food. HEF pays a standard amount (depending on the service provided) to the respective health facility, which then reinvests this amount in service delivery and staff bonuses. In 2017, over two million health facility visits were covered by HEF at both health centre and referral hospital level. ${ }^{23}$

As of 2018, the financing of HEF is shared between the Cambodian government and international donors, with a gradual transition towards exclusive government funding proposed by 2021.

people between services, or joint awareness raising on new benefits for identified beneficiaries, for example).

\section{Lessons learnt}

Many factors have contributed to IDPoor's role in supporting collaboration of both governmental and non-governmental programmes across sectors in ways that benefit poor women and children. A number of lessons can be drawn.

Firstly, contributions to improved $\mathrm{MCH}$ can be achieved without needing to be explicitly coordinated at the start of a programme. IDPoor has no MCH targets of its own, but nonetheless can contribute to improved outcomes by allowing other sectors, which do support mothers and children, to use its shared poverty data. Key factors enabling this process include the quality and credibility of data, as well as decisive government leadership. As Cambodia moves towards integration of all social assistance programmes under its national social protection strategy, IDPoor's role could be further strengthened by setting up a common monitoring framework for data users, as suggested at the multi-stakeholder review meeting. Incorporating regular reporting on standard indicators to clarify the impact and contribution of each sector, including health, would reinforce IDPoor as an active facilitator of interventions across sectors targeting poor women and children, among other vulnerable groups.

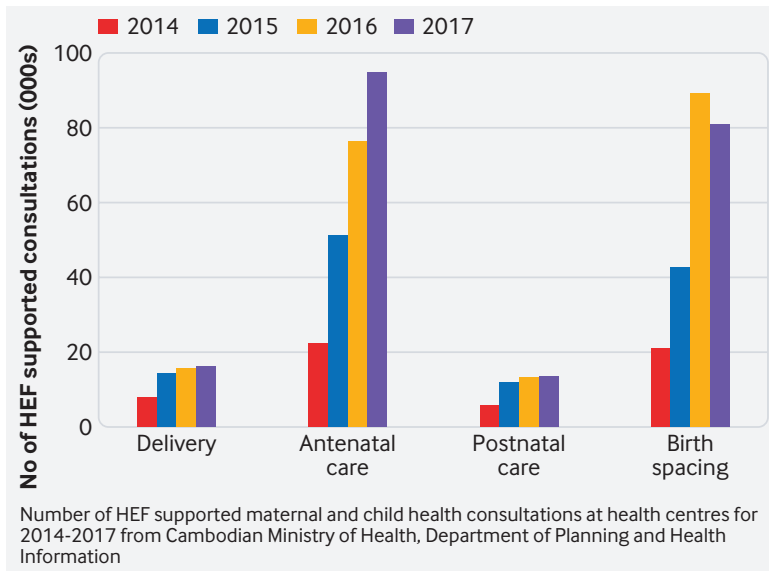

Fig 2 | Evolution of number of HEF patients using MCH services on health centre level

Secondly, our analysis supports the notion that cross cutting institutions are well placed to promote collaboration across sectors. ${ }^{13}$ The central and "sector neutral" role of MoP in Cambodia for IDPoor is linked to its mandate to provide demographic and other statistical data to development programmes. From this point of view, it can be argued that ministries of planning assume essential coordinating and administrative functions, which are qualitatively different from the functions of technical line ministries that oversee service delivery, and are thus often better able to engage with a variety of sectors and stakeholders.

Thirdly, we suggest that a shared target group and shared data can catalyse collaboration across sectors. IDPoor focuses the action of partners from different sectors on a common target group, the poor, including the goal of increasing access to $\mathrm{MCH}$ services to reduce disparities. For $\mathrm{MCH}$ actors in particular, the evolution of IDPoor towards a social protection system is an opportunity to harness the potential of data to reduce fragmentation and improve collaboration, such as in joint efforts of awareness raising about the services to which the equity card gives access.

Fourthly, the impact of interventions that require the input of multiple sectors needs to be assessed using a systems lens. The success of IDPoor in facilitating access of the poor to health and social services cannot be evaluated in isolation from the 


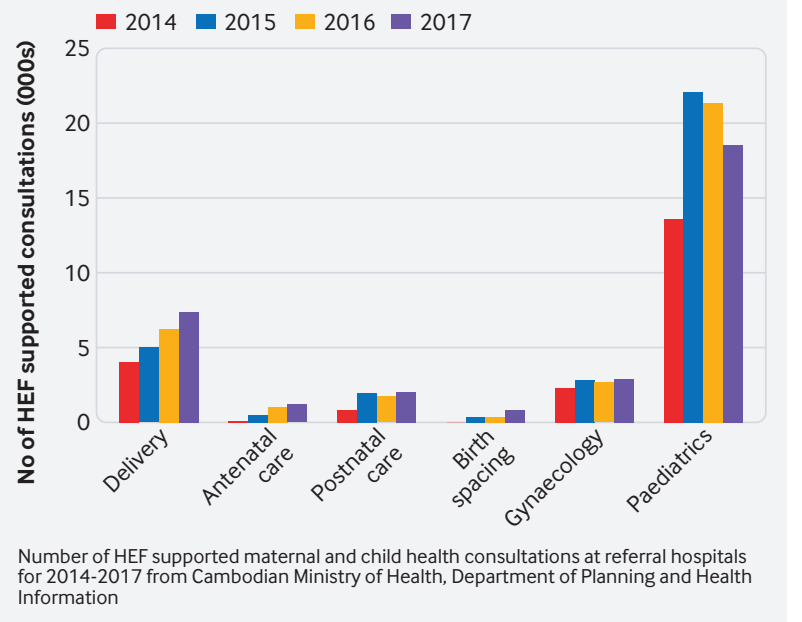

Fig 3 | Evolution of number of HEF patients using referral hospital services for delivery, ANC, PNC, birth spacing, gynaecology, and paediatrics, 2014-17

realities of the systems providing those services. While IDPoor facilitates increased formal access to services for the poor in programmes such as HEF, there is a need to tackle systems factors-both demand side and supply side-that influence service use that are independent of IDPoor, to maximise its impact on health and social outcomes.

Fifthly, there are a number of limitations and challenges that merit consideration and resolution in the development of IDPoor. Its three year data collection cycle-a compromise between cost effectiveness and real time accuracy-has been recognised as a crucial source of poverty data, but at present does not reflect sudden changes in household composition or poverty status. These can potentially be tackled through the On-Demand IDPoor mechanism currently being piloted.

Another limitation is the low availability of utilisation data across different sectors, which constrains IDPoor's potential for harmonisation, collaboration, and alignment among sectors and programmes. IDPoor's data are intentionally easy to access by registering on its website or through a direct request to MoP, but with the drawback that IDPoor does not retain full information about who is using its data, and for providing which services where.

These lessons and limitations should inform future development of IDPoor on its way to becoming the core of an integrated information system for social assistance. Capitalising on data user forums and consultation mechanisms and strengthening data analysis and reporting will be first steps. As the IDPoor database evolves, interoperability with other providers' databases will have to tackle these shortcomings, while ensuring confidentiality of the registered households.

We thank the many people who supported the preparation of this article, especially during the missions in Cambodia. Special thanks go to Cornelia Becker, programme manager, Improving Maternal and Newborn Care Project, GIZ, Phnom Penh, Cambodia, and Matthias Nachtnebel, health adviser at KfW Development Bank, Frankfurt, Germany. The authors thank, in Phnom Penh, Sar Kosal and Bou Vanna of the MoP IDPoor programme, Ole Doetinchem, Som Chandararith, and Kao Sopheap of the GIZ support project to IDPoor, Koeut Pichenda, Roith and So Serey of the MoH Payment Certification Agency, and Char Meng Chour of URC. Further information from GIZ in Phnom Penh was provided by Bernd Appelt, Vanny Peng, Kelvin Hui, and Bart Jacobs of the GIZ Social Health Protection Project, and Evi Gruber of the GIZ Multisectoral Food and Nutrition Security in Cambodia (MUSEFO) Project. We express our appreciation to all the organisations that attended the case study multi-stakeholder dialogue workshop on 21 June 2018, and particularly Inna Sacci, head of the USAID/ Save the Children NOURISH Project, and Maki Kato, chief of social inclusion and governance, UNICEF, who provided additional information. For support during fieldwork, the authors thank GIZ staff in Kampong Thom Province (Sorn Nora and Bunnareth Tuot), Ky Long of the MoP IDPoor programme, Phauk Chansetha, director of the Provincial Department of Planning, Pek Kim San, deputy director of the Provincial Health Department, Lim Sunnbunhong, director of the Kampong Thom Provincial Referral Hospital and staff from the Referral Hospital and the Tain Krosain Health Centre as well as the Tain Krosain Commune Council. Special thanks go to Oliver Schell, fieldwork translator.

Contributors and sources: This article is based on findings from a review of the multisectoral collaborative work of the IDPoor programme of Cambodia's Ministry of Planning in collaboration with the Ministry of Health. It is commissioned by the Partnership for Maternal, Newborn and Child Health Secretariat (hosted by WHO) to which all authors contributed. MWK, KB, SC, BS, and LB conceived the outline of this paper and MWK drafted the first version, and revised it in consultation with all authors including BP, SB, OK, RT, KC, and KR. SC and KB provided references and initiated meetings to inform the case study development. For the case study supporting the findings of this article: MWK wrote the draft working paper with inputs from other authors; MWK and LB undertook key informant interviews; and $\mathrm{KB}$ and LB drafted an initial summary of findings used for consultation with stakeholders at a multistakeholder meeting in Phnom Penh, Cambodia. Figures showing use of health services by Health Equity Fund beneficiaries were based on Health Management Information System data provided by the Department of Planning and Health Information, Ministry of Health, Phnom Penh, Cambodia. All authors contributed intellectual content and approved the final version of this article for submission. $K B$ is the guarantor of this article.

Competing interests: We have read and understood $\mathrm{BMJ}$ policy on declaration of interests and declare the following: funding from the PMNCH Secretariat (LB) and from GIZ (MWK) for consultancy fees and related costs for undertaking the case study; employees of Ministry of Planning or GIZ and involved in the IDPoor Programme (BP, KB, SC, OK); and attendance at the PMNCH Partners Forum in December 2018 (KB, BP, LB). All other authors have no competing interests to declare. The authors alone are responsible for the views expressed in this article, which does not necessarily represent the views, decisions, or policies of the institutions with which the authors are affiliated.

Provenance and peer review: Commissioned; externally peer reviewed.

This article is part of a series proposed by the WHO Partnership for Maternal, Newborn, and Child Health and commissioned by The BMJ, which peer reviewed, edited, and made the decision to publish the article. Open access fees for the series are funded by WHO $\mathrm{PMNCH}$.

Mary White Kaba, independent consultant ${ }^{1}$

Klaus Baesel, adviser ${ }^{2}$

Bunnak Poch, secretary of state

Samnang Bun, chief ${ }^{4}$

Sabine Cerceau, adviser ${ }^{5}$

Louise Bury, independent consultant ${ }^{6}$

Bastian Schwarz, adviser ${ }^{7}$

Ouly Keo, director ${ }^{8}$

Rathavy Tung, director ${ }^{9}$

Kannitha Cheang, technical officer ${ }^{10}$

Kumanan Rasanathan, health systems coordinator ${ }^{10}$

\section{${ }^{1}$ Montreal, Canada}

${ }^{2}$ Improving Maternal and Newborn Care Project, Deutsche Gesellschaft für Internationale Zusammenarbeit (GIZ) GmbH, Phnom Penh, Cambodia ${ }^{3}$ Ministry of Planning, Phnom Penh, Cambodia ${ }^{4}$ Bureau of Health Economics and Financing, Department of Planning and Health Information, Ministry of Health, Phnom Penh, Cambodia

${ }^{5}$ Support to the Identification of Poor Households Programme in Cambodia Project, GIZ, Phnom Penh, Cambodia

${ }^{6}$ Global Research Consultancy, Ipswich, UK ${ }^{7}$ Sector Initiative Population Dynamics and Sexual and Reproductive Health and Rights, GIZ, Bonn, Germany ${ }^{8}$ Department of IDPoor, Ministry of Planning, Phnom Penh, Cambodia

${ }^{9}$ National Maternal and Child Health Centre, Ministry of Health, Phnom Penh, Cambodia 
${ }^{10}$ World Health Organization, Phnom Penh, Cambodia Correspondence to: Klaus Baesel klaus.baesel@giz.de

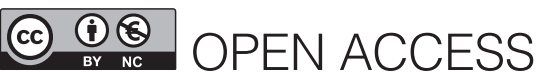

This is an Open Access article distributed under the terms of the Creative Commons Attribution IGO License (https://creativecommons.org/licenses/ by-nc/3.0/igo/), which permits use, distribution, and reproduction for non-commercial purposes in any medium, provided the original work is properly cited.

\section{Check for updates}

1 Ahmed SM, Rawal LB, Chowdhury SA, et al. Crosscountry analysis of strategies for achieving progress towards global goals for women's and children's health. Bull World Health Organ 2016;94:351-61. doi:10.2471/BLT.15.168450

2 World Health Organization. Health equity monitor: Cambodia. 2018. www.who.int/gho/health_equity/ countries/en.

3 Royal Government of Cambodia. Poverty in Cambodia: a new approach. Government report. 2013.

4 World Bank. Where have all the poor gone? 2014. http://documents.worldbank.org/ curated/en/824341468017405577/pdf/ ACS45450REVISEO0English0260May02014.pdf.

5 Leite P. Effective targeting for the poor and vulnerable. World Bank. 2014. http:// documents.worldbank.org/curated/ en/747591468125685125/Effective-Targetingfor-the-Poor-and-Vulnerable.

6 Barca V. Integrating data and information management. social registries and integrated beneficiary registries. Australian Government Department of Foreign Affairs. 2017. https://dfat.gov.au/about-us/publications/ Documents/integrating-data-informationmanagement-social-protection-full.pdf.

7 Kuruvilla S, Schweitzer J, Bishai D, et al. Success factors for reducing maternal and child mortality. Bull World Health Organ 2014;92:533-44. doi:10.2471/ BLT.14.138131
Cambodia Ministry of Health, Department of Planning and Health Information. Health Strategic Plan 20162020 (HSP3). Quality, Effective and Equitable Health Services, 2016.

9 Annear PL, Wilkinson D, Chean MR, van Pelt M. Study of financial access to health services for the poor in Cambodia. 2006. www.portal.pmnch.org/health financing/countries/cam-healthaccess.pdf.

10 BMZ. Leave no one behind: Insights from Cambodia's national poverty identification system. GHPC. BMZ 2017. https://health.bmz.de/ghpc/ case-studies/leave-no-one-behind/ID_POOR_Final_ lowres.pdf

11 Devereux S, Masset E, Sabates-Wheeler R, Samson M, Rivas AM, te Lintelo D. The targeting effectiveness of social transfers. / Dev Effect 2017;9:162-211. doi:10.1080/19439342.2 017.1305981.

12 World Bank. Assessment of the Identification of Poor Households (IDPoor). Program's Procedures and Implementation, 2012.

13 GIZ. IDPoor data user study. Market Strategy \& Development for GIZ, 2015.

14 OECD. Social Protection System Review of Cambodia, OECD Development Pathways, OECD Publishing, Paris. 2017. http://www.oecd.org/pensions/ social-protection-system-review-of-cambodia9789264282285-en.htm

15 KfW. Social Security in the event of illness (vouchers for reproductive healthcare services). Ex-post evaluation, Cambodia. Frankfurt. 2015. www. kfw-entwicklungsbank.de/International-financing/ KfW-Development-Bank/Our-results/Results/Ex-PostEvaluation-Reports-C-D/

16 Save the Children. NOURISH Project. Mid-Term Survey Report. 2018

17 Unicef. Evaluation of the CARD and UNICEF Cash Transfer Pilot Project for Pregnant Women and Children in Cambodia. Evaluation Brief. 2018. https://www.unicef.org/cambodia/2018-04-30Formative-Evaluation-Cash-Brief(Eng).pdf

18 Ministry of Planning. IDPoor Information System, Internal Database. 2018. www.idpoor.gov.kh/en/ home

19 Flores G, Ir P, Men CR, O'Donnell O, van Doorslaer E. Financial protection of patients through compensation of providers: the impact of Health Equity Funds in Cambodia. J Health Econ 2013;32:1180-93. doi:10.1016/j. jhealeco.2013.09.012
20 Ensor T, Chhun C, Kimsun T, McPake B, Edoka I. Impact of health financing policies in Cambodia: A 20 year experience. Soc Sci Med 2017;177:118-26. doi:10.1016/j.socscimed.2017.01.034

21 Kingdom of Cambodia. National social protection policy framework 2016-2025. Government report. 2017.

22 Cambodia Ministry of Health, Department of Planning and Health Information. Guidelines for the benefit package and provider payment of the Health Equity Fund for the Poor. Government report. 2018.

23 Cambodia Ministry of Health, Department of Planning and Health Information. Health information system, internal database. Government report. 2018

24 World Bank. Utilization and impact of health equity funds. improving entitled benefits uptake by the poor. Government report. 2016.

25 Hardeman W, Van Damme W, Van Pelt M, Por I, Kimvan $H$, Meessen B. Access to health care for all? User fees plus a Health Equity Fund in Sotnikum, Cambodia. Health Policy Plan 2004;19:22-32. doi:10.1093/heapol/czh003

26 Cambodia Ministry of Planning, National Institute of Statistics. Socio-Economic Survey 2016. 2017. www. nis.gov.kh/nis/CSES/Final\%20Report\%20CSES\%20 2016.pdf.

27 World Health Organization, Regional Office for the Western Pacific. The Kingdom of Cambodia health system review. 2015. http://iris.wpro.who.int/bitstream/ handle/10665.1/11356/9789290616917_eng.pd

Supplement 1: Maternal and child health and poverty in Cambodia

Supplement 2: Methods for IDPoor case study

Supplement 3: Criteria used in identification of poor households by IDPoor Supplement 4: Partner programmes through which IDPoor contributes to maternal and child health

See www.bmj.com/multisectoral-collaboration for other articles in the series.

Cite this as: $B M / 2018 ; 363: k 4698$

http://dx.doi.org/10.1136/bmj.k4698 